\title{
Toward an understanding of global health inequality
}

Awakening Hippocrates: a primer on health, poverty, and global service Edward O'Neil, Jr.

American Medical Association; 2006

507 pp US\$34.95 ISBN: 1-57947-772-0

A $\mathrm{s}$ a preceptor to medical students and residents, I am often approached by those wanting to take their medical skills abroad. I have worked in international development for 25 years and I welcome this desire to share our good fortune to be born in a wealthy, developed country with those less privileged countries. However, I also know that to be effective when working in health overseas one must have a broad understanding of the issues that make this work necessary.

The recent 2006 International HIV/AIDS conference in Toronto has heightened awareness in Canada that diseases that have reached epidemic proportions overseas are a threat to everyone in the world, not just to those living in places where the death rate from the disease is high. No part of the world today is further than 36 hours away from any other part of the world.

There is an enormous need for skilled medical workers in developing countries, but very often these countries cannot provide enough of these workers. Why not? We all know they need our help, but what most of us don't understand is just why they have a shortage of medical workers. While another book, Where There Is No Doctor, ${ }^{1}$ is a very useful text, up to now there hasn't been a book answer-

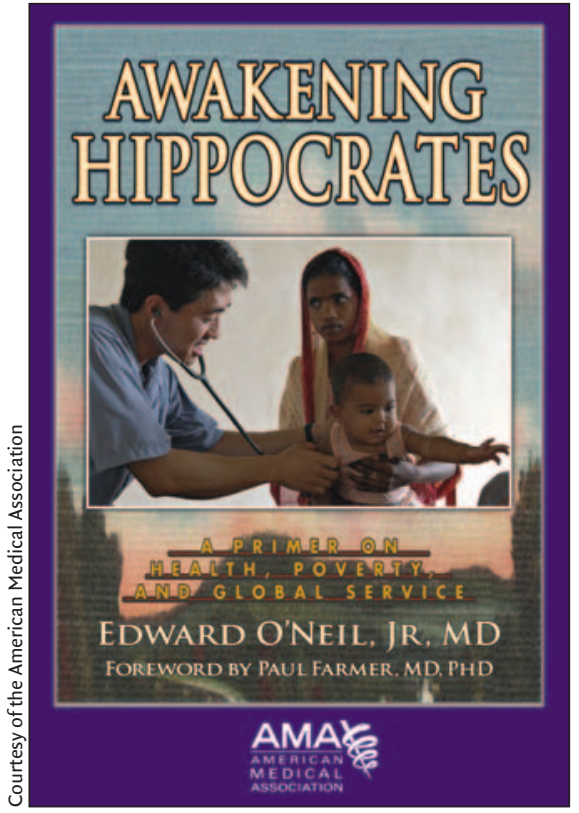

ing the question "Why is there no doctor?"

Awakening Hippocrates is not only aimed at health care workers. It is intended for anyone interested in understanding why some of us in the world live very long, comfortable lives and others die young, often from fairly easily preventable causes. As O'Neil states in the introduction, to understand why this is so the reader must first "understand the complex world of trade relations, history, racism, sexism, foreign aid flows, development, governance and global financial flows, among others, all of which conspire to perpetuate poverty." The book gives elaborate and detailed dissertations on all of these topics. Although heavily weighted toward a US perspective on these issues, with much more discussion of US organizations and influence than other countries' efforts in the developing world, it does give an excellent understanding of development issues as a whole. Non-Americans reading this book will have to do so with the knowledge that the author is American and that the enormous economic might of the United States has made it a major player in this issue. It's not, however, the only player. This book does give adequate credit to all countries but it gives an inordinate amount of space to the history and details of US organizations and branches of government.

The chapter entitled "The rise of health in the industrialized world" outlines why developing countries have been able to build up health care for citizens to the level we have here in Canada, for example. Then it looks at why this hasn't been possible everywhere.

Chapter 3 looks at knowledge diffusion whereby poor countries can, or should be able to, learn from the example of rich countries. It looks at the United Nations, particularly the World Health Organization, as well as the non-governmental organization (NGO) sector, their successes and their failures. It points out that while there have been many advances, these organizations have also committed "harmful actions under the veil of humanitarianism."

One of the most interesting chapters outlines the roles of the World Bank and the International Monetary Fund. It doesn't mince words in condemning these organizations' part in very nearly causing the collapse of the global monetary system through unrestrained lending. The poor countries who were 
the beneficiaries of this largesse are now having to repay their debts through "World Bank-IMF sponsored structural adjustment programs in which services to the poor were cut, dramatically worsening their health and longevity." such as malaria, tuberculosis and a host of others sicken and kill the poor and undernourished in much greater numbers than others and slow the economic growth of entire world regions. HIV/AIDS has its own chapter in the book, for obvious reasons, as

\section{No part of the world today is fur- ther than 36 hours away from any other part of the world.}

The other chapters cover "the financial forces that foster an unequal and unsustainable world economic order" such as trade barriers and subsidies. They elaborate on how maintaining the inequality between rich and poor everywhere leads to vastly differing incidences of disease and life expectancy. Poor governance, racism and sexism further exacerbate this difference, and these issues are clearly explained and elaborated. One has just to look at examples such as Zimbabwe or Afghanistan to see how these forces have worked for so long to keep so many mired in misery. The plight of children is outlined very well. Then there is the terrible quandary of women in so many countries as the most discriminatedagainst group in the world right now. Stephen Lewis has been very vocal on this issue in the light of the disproportionate incidence of HIV/AIDS among women in developing countries, and this book forcefully supports his statements.

Population growth is another area where the poor suffer most. In order to have at least one child grow up and get a job so that you have someone to care for you in old age in countries where the death rate among children under 5 is often around 50\% and unemployment is even higher, people have to have ro children or more. How can you escape poverty in a situation like that? Then there are the immovable forces of nature and geography that often contribute to the perpetuation of poverty. Diseases does Ethics, Human Rights and Religion - all of which have for so long been instrumental in both helping and harming mankind.

The book ends with excellent synopses of the lives of medical legends

\section{Poem}

\section{The mother}

She huddles by the roadside

Scared of the sleek, passing limousines

Her clothes have seen better days

The child on her hips, clothed in rags

The child howls, her brow clouded with sweat

The child slowly sobs herself to sleep

Will she wake up to see another day?

\section{P. Ravi Shankar, MD \\ Pokhara, Nepal}

such as Drs. Albert Schweitzer and Tom Dooley as well as those lesser known, but equally deserving of praise, such as Drs. Bill Fryda, Peter Allen and Thomas Durant. Role models are valuable for all of us, and reading of these doctors' accomplishments overseas will be an inspiration to many in the medical profession who want to work where the need for them is so desperate.

I hope this book will help move many to do just that, while providing an excellent understanding as to just why this help is needed.

\section{Robert J. Birnbaum \\ Family physician \\ Ottawa, Ont.}

\section{REFERENCE}

I. Werner D. Where there is no doctor. Palo Alto (CA): Hesperian Foundation; 1977.

The mother tries to comfort, offers a chunk of jaggery

The child is feverish, her breathing rapid and shallow

Clinics and hospitals with their imposing glass facades line the street

The best modern medicine has to offer beneath their roofs

The mother, poor, by the door; money is a cruel gatekeeper

Tools for eternal youth and beauty, everlasting health

The wretched mother too poor to afford even a bottle of paracetamol

She gently rocks the child, sings a lilting lullaby 